Article

\title{
The Fusarium Circinatum Gene Fcrho1, Encoding a Putative Rho1 GTPase, Is Involved in Vegetative Growth but Dispensable for Pathogenic Development
}

\author{
E. Jordán Muñoz-Adalia ${ }^{1,2, *}$, M. Carmen Cañizares ${ }^{3}$, Mercedes Fernández ${ }^{1,4}{ }^{\circledR}$, \\ Julio J. Diez ${ }^{1,2}$ and M. Dolores García-Pedrajas ${ }^{3}$ \\ 1 Sustainable Forest Management Research Institute, University of Valladolid-INIA, \\ Avenida de Madrid 44, 34004 Palencia, Spain; mffernan@agro.uva.es (M.F.); jdcasero@pvs.uva.es (J.J.D.) \\ 2 Department of Vegetal Production and Forest Resources, University of Valladolid, \\ Avenida de Madrid 44, 34004 Palencia, Spain \\ 3 Instituto de Hortofruticultura Subtropical y Mediterránea "La Mayora"-Universidad de \\ Málaga-Consejo Superior de Investigaciones Científicas (IHSM-UMA-CSIC), \\ Estación Experimental “La Mayora”, Algarrobo-Costa, 29750 Málaga, Spain; \\ carmen.canizares@eelm.csic.es (M.C.C.); mariola@eelm.csic.es (M.D.G.-P.) \\ 4 Department of Agroforestry Sciences, University of Valladolid, Avenida de Madrid 44, 34004 Palencia, Spain \\ * Correspondence: emigdiojordan.munoz@uva.es or ejordanmunoz@hotmail.com; Tel.: +34-979-108432
}

Received: 5 October 2018; Accepted: 29 October 2018; Published: 31 October 2018

\begin{abstract}
Fusarium circinatum is the causal agent of pine pitch canker (PPC), one of the most devastating forest diseases worldwide. This fungus causes severe damping-off in pine seedlings and growth reduction, wilting and the development of cankers in pine forests and plantations. A draft of the complete genome sequence of this phytopathogen was recently made available. This information was used to annotate in silico the gene Fcrho1 as a putative homolog of Rho1 GTPase genes. In this study, we generated Fcrho1 deletion mutants in two F. circinatum wildtype strains isolated from damaged trees in northern Spain. For that, we used a modified version of the OSCAR methodology, an approach not previously used in F. circinatum that allows the generation of deletion constructs in a single cloning step. The conidiation and spore germination of the resulting deletion mutants were not affected, neither the hyphal morphology. However, the mutant strains showed significantly reduced growth in vitro and more foamy macroscopic hyphal morphology than their corresponding ectopic and wildtype strains. Finally, an in vivo virulence assay showed that the reduced in vitro growth rate characteristic to the deletion mutants does not impact their pathogenicity.
\end{abstract}

Keywords: cell signalling; deletion mutant; in planta virulence; OSCAR protocol; Pinus radiata; pine pitch canker

\section{Introduction}

Fusarium circinatum Nirenberg and $\mathrm{O}^{\prime}$ Donell is the causal agent of pine pitch canker disease (PPC). This species is present in 14 countries throughout Africa, America, Asia and Europe and has become a major threat to coniferous forests, plantations and nurseries worldwide [1]. It causes high rates of mortality in Pinus spp. and Pseudotsuga menziesii (Mirb.) Franco seedlings as well as reduced growth, the occurrence of resin-soaked cankers, and intense wilting in mature trees. This disease severely reduces both, the value and the yield of the timber, leading to important economic losses [2]. F. circinatum acts as a necrotroph when it infects coniferous plants via the stem; however, the molecular 
mechanisms of fungal infection is largely unknown. Five candidate genes putatively associated with pathogenicity have recently been annotated in silico [3] by using the complete fungal genome as a query [4]. Functional studies are, however, required for definitive characterization of each gene.

One of the five candidate genes annotated in F. circinatum is a Rho-type GTPase termed Fcrho1 [3]. The mitogen-activated protein kinase (MAPK) cascades are a crucial signalling pathway in eukaryotes which triggers cellular responses associated with a wide range of external stimuli (e.g., environmental chemical conditions, pheromones, etc.). MAPK signalling involves participation of the small Rho-type GTPases proteins that play an essential role in cell growth polarity by regulating the organization of the actin cytoskeleton and participating in the formation of hyphal structures [5,6]. These functions make GTPases particularly important in fungal pathogenesis, as abnormal formation of infective structures (e.g., appressoria) [7] or ineffective mycelial morphogenesis [8] can drastically reduce the effectiveness of host colonization. In the grass pathogen Claviceps purpurea (Fr.) Tul. deletion of the GTPase Rac gene caused excessive branching and absence of polarity in mycelial growth which resulted in avirulence in mutant strains [9]. Several Rho proteins have been characterized in pathogenic species of Fusarium. For instance, in Fusarium oxysporum f. sp. lycopersici (Sacc.) W.C. Snyder and H.N., the Rho1 gene has been shown to regulate in planta virulence as well as the cell wall response to lytic enzymes [10]. Bluhm et al. [11] studied the function of the GTPase-encoding gene RAS2 in Fusarium graminearum Schwabe, and observed that its deletion resulted in slower mycelial growth and reduction in virulence in wheat (Triticum sp.). A later study also reported attenuated virulence in fungal strains of this phytopathogen lacking Rho subfamily members [12]. Hence, study of this family of proteins can contribute to a better understanding of how cellular signalling regulates phenotypic responses during plant infection.

Lack of knowledge about the genes that drive virulence traits in this phytopathogen demands new research. Therefore, the aims of this study were (i) to generate deletion mutants of the putative Rho1 GTPase gene Fcrho1 in F. circinatum and (ii) to evaluate the phenotypic effects of gene deletion both in vitro and in vivo.

\section{Materials and Methods}

\subsection{Fungal Material and Growth Conditions}

Two wildtype isolates of F. circinatum were selected for the study (i.e., Fc072 and 011). Both were isolated from symptomatic Monterey pines (Pinus radiata D. Don) in northern Spain [13]. The isolates were grown in $100 \mathrm{~mL}$ of YEPS (Appendix A) at $25^{\circ} \mathrm{C}$ and 200 r.p.m. shaking for five days (SI600-R cooled shaking incubator; Lab Companion, Billerica, MA, USA). Both cultures were filtered using sterilized Miracloth tissues (Sigma Aldrich, Darmstadt, Germany), and the collected mycelium was ground in liquid nitrogen for each isolate separately in a sterile mortar. The genomic DNA was extracted using a Plant DNA kit (Bioline, London, UK) according to the manufacturer's instructions.

\subsection{Generation of Fcrho1 Deletion Construct}

A modified version of the OSCAR protocol described by Paz et al. [14] and Gold et al. [15] was used to generate a construct to delete the entire open reading frame (ORF) of Fcrho1. Briefly, specific primers were designed to amplify 1000 nucleotides (nt) of the $3^{\prime}$ and $5^{\prime}$ regions flanking the Fcrho1 ORF. Primers were designed on the basis of the sequence reported by Muñoz-Adalia et al. [3] by using primer3 software [16]. Primers included att-tails as described by Paz et al. [14] (Table 1). Flanking regions were then amplified by polymerase chain reaction (PCR) using BioTaq ${ }^{\mathrm{TM}}$ DNA Polymerase (Bioline, London, UK) according to manufacturer's instructions with genomic DNA from isolate Fc072 as a template. PCR conditions were as follows: $30 \mathrm{~s}$ at $98^{\circ} \mathrm{C}$ followed by 10 touchdown cycles of $20 \mathrm{~s}$ at $98^{\circ} \mathrm{C}, 20 \mathrm{~s}$ at $66^{\circ} \mathrm{C}$ (annealing temperature was decreased at a rate of $-0.8^{\circ} \mathrm{C} / \mathrm{cycle}$ ) and $60 \mathrm{~s}$ at $72{ }^{\circ} \mathrm{C}$, and then, a total of 25 cycles of $20 \mathrm{~s}$ at $98{ }^{\circ} \mathrm{C}, 20 \mathrm{~s}$ at $58^{\circ} \mathrm{C}$ and $60 \mathrm{~s}$ at $72{ }^{\circ} \mathrm{C}$ with a final elongation step of $5 \mathrm{~min}$ at $72{ }^{\circ} \mathrm{C}$. To confirm the amplification of the correct size bands, PCR products were 
then subjected to electrophoresis in $1 \% w / v$ borate-agarose gel staining with $2 \times 10^{-3} \% v / v$ ethidium bromide (Merck, Darmstadt, Germany) and then visualized under ultraviolet (UV) light. After that, both PCR fragments were purified using NucleoSpin ${ }^{\circledR}$ Gel and PCR Clean-up kit (Macherey-Nagel, Düren, Germany) according to the manufacturer's instructions. A BP clonase reaction was then set up to generate the deletion construct according to Paz et al. [14] and García-Pedrajas et al. [17]. The BP clonase reaction contained the purified PCR products, a binary vector compatible with Agrobacterium tumefaciens Smith and Townsend-mediated transformation (ATMT), and a second plasmid containing the marker $h y g R$ conferring resistance to hygromycin B. The binary vector used, pOSCAR-HSVtk, is a variant of pOSCAR [14] to which the herpes simplex virus (HSV) thymidine kinase gene HSVtk [18] was included to prevent ectopic integration of the transforming T-DNA. The second vector used was pA-Hyg-OSCAR a modified version of pA-Hyg-GFP-OSCAR which contains green fluorescent protein (GFP) cassette for GFP-tagging of deletion mutants [19]. The gene flanks and vectors were incubated with BP clonase (Invitrogen, Carlsbad, CA, USA) at $25^{\circ} \mathrm{C}$ for $16 \mathrm{~h}$. The BP clonase recognizes specific recombination sequences present in the amplified gene flanks and vectors, generating the target construction (Figure 1). Resulting constructs were transformed into Escherichia coli Escherich using a standard heat shock method. Escherichia coli transformants were selected on LB medium plates supplemented with $0.06 \% \mathrm{w} / \mathrm{v}$ spectinomycin (Appendix A). Plates were incubated for $12 \mathrm{~h}$ at $37^{\circ} \mathrm{C}$ to allow the transformants to grow.

Table 1. Primer pairs used in this study. Flanking regions of the Fcrho1 target gene were amplified using specific primers including att-tails (denoted in bold); nt, nucleotides.

\begin{tabular}{|c|c|c|c|}
\hline Primer Pair & Sequences $\left(5^{\prime}-3^{\prime}\right)$ & Size & Region \\
\hline FcirRHO1j & TATGCGTTGATGCTCTGAGG & \multirow{2}{*}{$855 \mathrm{nt}$} & \multirow{2}{*}{ Exon of Fcrho1 } \\
\hline FcirRHO2q & TCCAGCTCTCCAAGCTCTTC & & \\
\hline HygF_Oscar & AAAGCCTGAACTCACCGCGACG & \multirow{2}{*}{$736 \mathrm{nt}$} & \multirow{2}{*}{$h y g R$ marker } \\
\hline HygR_Oscar & AGCGCGTCTGCTGCTCCATAC & & \\
\hline FRHO11j-attB2r & GGGGACAGCTTTCTTGTACAAAGTGGAAAATTGCCATGGTACGAGAGGCT & \multirow{2}{*}{$940 \mathrm{nt}$} & \multirow{2}{*}{$5^{\prime}$ flanking region of Fcrho1 } \\
\hline FRHOl2q-attB1r & GGGGACTGCTTTTTTGTACAAACTTGTTTAAGGTTCCATGCCCAAGAGG & & \\
\hline FRHOr1j-attB4 & GGGGACAACTTTGTATAGAAAAGTTGTTAACATGATACCCAGCTCCATCG & \multirow{2}{*}{$873 \mathrm{nt}$} & \multirow{2}{*}{$3^{\prime}$ flanking region of Fcrho1 } \\
\hline FRHOr2q-attB3 & GGGGACAACTTTGTATAATAAAGTTGTGATCCCGCTGACGTGAGTATTG & & \\
\hline
\end{tabular}

To analyze the plasmid DNA of emerging colonies of E. coli and identify those confirmed to carry the correct deletion construct, individual colonies were inoculated in $3 \mathrm{~mL}$ of liquid LB medium amended with spectinomycin. Bacterial cells were then mixed with TENS buffer (Appendix A) and $3 \mathrm{M}$ sodium acetate and centrifuged for $5 \mathrm{~min}$ at 14,000 r.p.m. (rotor radius: $7 \mathrm{~cm}$ ). The resulting plasmid DNA pellets were washed with $70 \% v / v$ ethanol and dried at $37^{\circ} \mathrm{C}$ for $20 \mathrm{~min}$. Purified DNA was resuspended in double sterilized water (dsw) and digested with the Pst1 restriction enzyme (FastDigest, Fermentas, Vilnius, Lithuania) for $2 \mathrm{~h}$ at $35^{\circ} \mathrm{C}$. Digested DNA fragments were run on an agarose gel as previously described to determine the pattern of bands (i.e., four bands pattern: $\sim 9.50 \mathrm{~kb}, 2.90 \mathrm{~kb}$, $1.65 \mathrm{~kb}$ and $1.30 \mathrm{~kb}$; Figure 1). A plasmid DNA with expected digestion pattern of Fcrho1 deletion construct was further purified using the NucleoSpin ${ }^{\odot}$ Plasmid Easy Pure kit (Macherey-Nagel, Düren, Germany) and transformed into A. tumefaciens strain AGL-1 [20] by electroporation in a GenePulser Xcell (BioRad, Hercules, CA, USA). Bacteria were incubated in liquid LB medium at $28{ }^{\circ} \mathrm{C}$ for $2 \mathrm{~h}$ prior to selection of transformants on LB plates amended with spectinomycin. These plates were incubated for $48 \mathrm{~h}$ at $28^{\circ} \mathrm{C}$ at which point the emergence of colonies resistant to spectinomycin was observed. A single bacterial colony harboring the Fcrho1 deletion construct was reserved for ATMT transformation of F. circinatum as described below. 


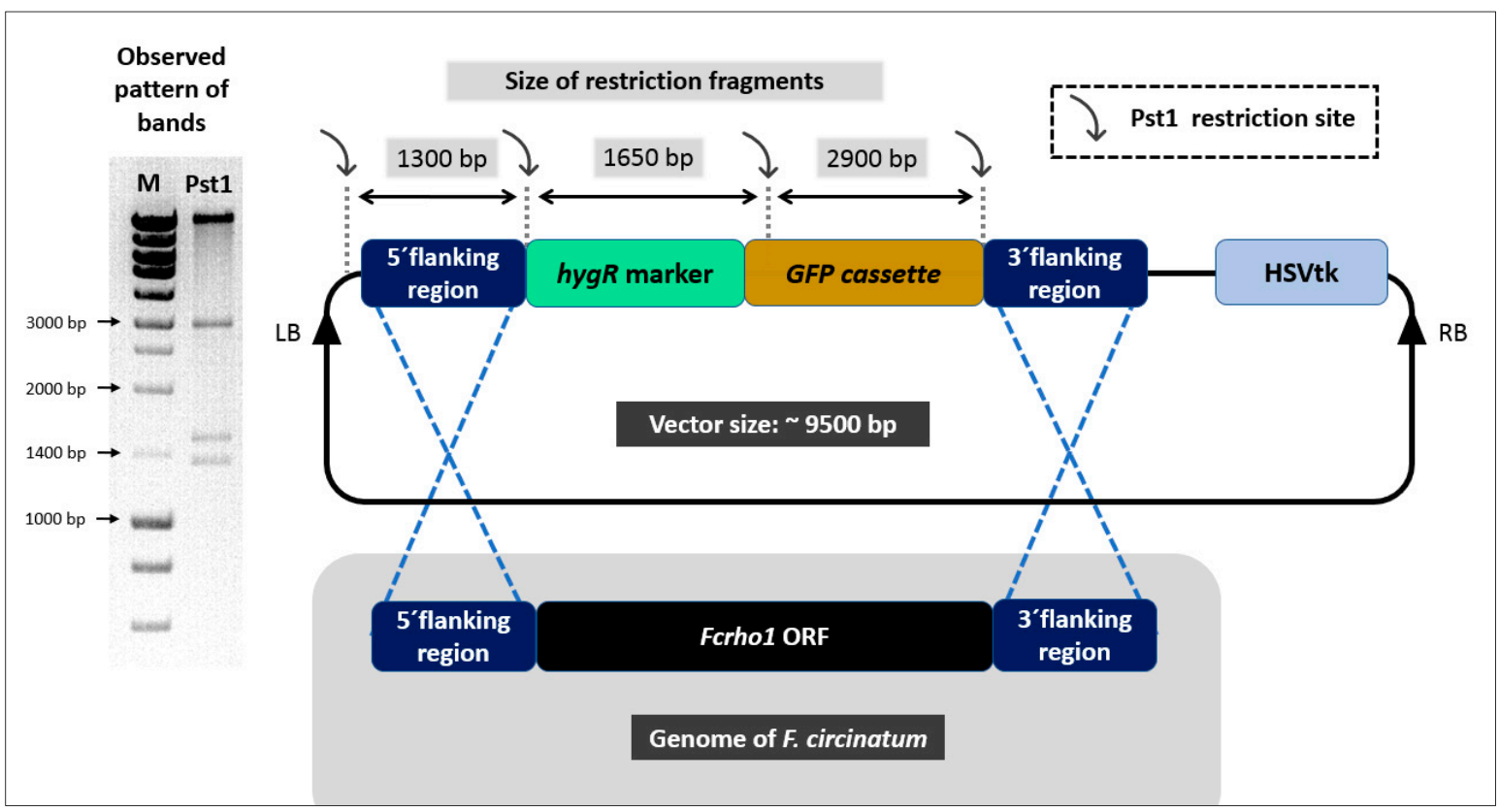

Figure 1. Deletion construction formed using a modified version of the OSCAR protocol. LB/RB: left/right border. M: NZYDNA Ladder III; Pst1: band pattern obtained after DNA digestion with Pst1 restriction enzyme.

\subsection{Transformation of F. circinatum with Fcrho1 Deletion Construct}

Conidial suspensions of F. circinatum were prepared for transformation with the deletion construct, using an ATMT method [14]. For that, F. circinatum wildtype strains were grown in YEPS medium (Appendix A) for one week at $24^{\circ} \mathrm{C}$ and 200 r.p.m. From these cultures, conidia were collected by filtration using sterilized Miracloth and centrifugation at 8000 r.p.m. (rotor radius $10.10 \mathrm{~cm}$ ) at room temperature for $10 \mathrm{~min}$. The resulting pellet was resuspended in $500 \mu \mathrm{L}$ of dsw and the conidia were counted using a haemocytometer under light microscope $(25 \times$ lens, Zeiss, Oberkochen, Germany). The final concentration of conidia was adjusted to $10^{7}$ spores $/ \mathrm{mL}$.

In parallel, the A. tumefaciens AGL-1 cells previously transformed with Fcrho1 deletion construct, were grown in minimum medium (Appendix A) at $24{ }^{\circ} \mathrm{C}$ and 200 r.p.m. until the culture reached an optic density of $0.50-0.80(K=600 \mathrm{~nm}$; GeneQuant pro; GE Healthcare Life Sciences, Uppsala, Sweden). At that point, $100 \mu \mathrm{L}$ of each conidial suspension and $100 \mu \mathrm{L}$ of bacterial culture were mixed in sterile $1.50 \mathrm{~mL}$ tubes and then spread on a sterile nitrocellulose film placed on a Petri dish containing induction medium (Appendix A) amended with $200 \mu \mathrm{M}$ acetosyringone (Sigma Aldrich, Darmstadt, Germany). Plates containing the mixed cultures were incubated in the dark at $24{ }^{\circ} \mathrm{C}$ for two days. Then, strips of nitrocellulose were cut using a sterile scalpel and transferred to plates of selection medium amended with $150 \mu \mathrm{g} / \mathrm{mL}$ of hygromycin B (Sigma Aldrich, Darmstadt, Germany) and three additional antibiotics as shown in Appendix A. The putative transformants of F. circinatum, emerging at the edges of the nitrocellulose strips, were transferred to potato-dextrose-agar medium (PDA; Appendix A) amended with $150 \mu \mathrm{g} / \mathrm{mL}$ of hygromycin B (Appendix A) and then subcultured twice in the same medium to ensure mitotic stability of transforming DNA containing the $h y g R$ marker.

\subsection{Confirmation of Deletion Mutants}

The effective deletion of the target gene in individual transformants was determined by PCR. For that, total DNA was extracted from each transformant according to the method described by Vainio et al. [21] and used for PCR with the primer pair FcirRHO1j/FcirRHO2q which amplify part of the Fcrho1 ORF (Table 1). PCR was performed under the following conditions: 2 min at $95{ }^{\circ} \mathrm{C}$ followed by 35 cycles of $35 \mathrm{~s}$ at $95{ }^{\circ} \mathrm{C}, 40 \mathrm{~s}$ at $55^{\circ} \mathrm{C}$ and $1 \mathrm{~min}$ at $72{ }^{\circ} \mathrm{C}$; the final elongation step 
consisted of $7 \mathrm{~min}$ at $72{ }^{\circ} \mathrm{C}$. The insertion of the $h y g R$ marker was also analyzed either in mutant or in ectopic strains (i.e., fungal strains in which the deletion construct did not integrate by homologous recombination replacing the target gene by the $h y g R$ cassette but randomly in the fungal genome) by PCR using primer pair HygF_Oscar/HygR_Oscar and the following program: $3 \mathrm{~min}$ at $95^{\circ} \mathrm{C}$ followed by 35 cycles of $30 \mathrm{~s}$ at $95{ }^{\circ} \mathrm{C}, 30 \mathrm{~s}$ at $58^{\circ} \mathrm{C}$ and $50 \mathrm{~s}$ at $72{ }^{\circ} \mathrm{C}$; the last step extended $5 \mathrm{~min}$ at $72{ }^{\circ} \mathrm{C}$. Reagents and electrophoresis conditions were the same as described above. A single transformant with a confirmed deletion of Fcrho1 gene was selected for both F. circinatum strains used (Fc072 and 011); they are referred to as $\Delta F c r h o 1 F c 072$ and $\Delta F c r h o 1011$, according to their genetic background. A transformant with ectopic integration of the deletion construct, i.e., carrying an intact Fcrho1 gene, was also selected for each genetic background. These strains, referred to as Fc072ect2 and 011ect5, were used as controls to discard any potential effect of the transformation procedure on the F. circinatum phenotypic characteristics.

\subsection{Analysis of Hyphal Growth and Conidiation}

At first, we determined whether the lack of Fcrho1 had an effect on the colony growth rate on solid medium. For that, parental wildtype strains Fc072 and 011, deletion mutants $\Delta$ Fcrho1Fc072 and $\Delta$ Fcrho1011 and their corresponding ectopic strains, Fc072ect2 and 011ect5, respectively, were grown on PDA. The growth test included six plates per strain incubated at room conditions $\left(23^{\circ} \mathrm{C} \pm 2{ }^{\circ} \mathrm{C}\right.$; 10-11 h of light per day) for one week. The size of each colony was calculated daily by measuring two perpendicular axes and calculating the area of the corresponding ellipse $\left(A_{c}\right)$. The mean growth rate (G) was calculated as the mean value of colony size increase between two consecutive observations.

The same plates were also used to determine whether the lack of Fcrho1 affects hyphal morphology. For that, $5 \times 5 \mathrm{~mm}$ plugs comprising mycelium and PDA medium were cut from four 40-day-old replica plates of each strain. Then, all the samples obtained from each strain were mixed in $50 \mathrm{~mL}$ sterile tubes containing $10 \mathrm{~mL}$ of dsw. Tubes were incubated at $25{ }^{\circ} \mathrm{C}$ and 280 r.p.m. for $4 \mathrm{~min}$ and then briefly centrifuged at 7000 r.p.m. using swinging bucket rotor (rotor radius: $7.50 \mathrm{~cm}$ ). An amount of $20 \mu \mathrm{L}$ of water containing hyphae were collected from the bottom of the tube and transferred to a haemocytometer with a sterile pipette tip. The hyphae structure was inspected under a light microscope $(40 \times$ lens, Nikon; camera: COOLPIX 4500; Tokyo, Japan). Fifteen additional plugs were collected per strain and cultured in five $50 \mathrm{~mL}$ crystal flasks (three plugs per flask) containing $20 \mathrm{~mL}$ of potato-dextrose-broth (PDB; Appendix A). Liquid cultures were incubated at room temperature with shaking (180 r.p.m.) for 48 h. The number of microconidia (C) and germlings (N) was estimated three times per culture under a light microscope as explained for hyphae analysis.

\subsection{Pathogenicity Assay}

An in vivo pathogenicity test was performed using 75 three-year-old seedlings of $P$. radiata (i.e., 10 plants per fungal strain to be inoculated and 15 plants for control: mean height of plants and standard error: $55.62 \pm 2.29 \mathrm{~cm}$ ). A fortnight period of acclimatization at $25^{\circ} \mathrm{C}$ and photoperiod of $16 \mathrm{~h}$ was used prior to the actual experiment. Pine seedlings were watered three times a week with equal amounts of tap water during the entire assay. Inoculation involved an incision two centimeters above the root collar made with a sterile scalpel and applying a droplet of $10 \mu \mathrm{L}$ of the spore suspension $\left(10^{6}\right.$ conidia $\left./ \mathrm{mL}\right)$ into the wound. The conidial suspensions of each fungal strain were obtained using liquid PDB cultures as described above. Control plants were inoculated with the same volume of dsw. The wound was covered with Parafilm ${ }^{\circledR}$ for one week. Both inoculated and control seedlings were held in separate plant growth chambers to avoid cross-contamination. The severity of symptoms was monitored after two weeks of infection according to the 0-4 qualitative scale of symptoms described by Correll et al. [22]. The intensity of symptoms in each plant was measured every two days from the appearance of symptomatology until 30 days post inoculation (dpi). The data for each seedling were used to calculate the area under the disease progress curve (AUDPC) as previously described $[23,24]$. 
One third of seedlings per inoculated treatment (i.e., dead or dying plants) were selected for re-isolation of F. circinatum. Stems were cut into small pieces from two centimeters above the inoculation point and washed by immersion in dsw for $60 \mathrm{~s}$. The samples were then surface sterilized by soaking in $70 \% v / v$ ethanol (PanReac Química, Barcelona, Spain) for $60 \mathrm{~s}$ and then in $2 \% v / v$ sodium hypochlorite (PanReac Química, Barcelona, Spain) for another minute. Finally, the samples were washed again in dsw for $60 \mathrm{~s}$ and plated either on PDA or on Spezieller Nährstoffarmer agar medium [25] for morphological identification.

\subsection{Statistical Analysis}

The variations in growth rate $(G)$, area of colony $\left(A_{c}\right)$, number of microconidia $(C)$, number of germlings $(\mathrm{N})$ as well as area under the disease progress curve (AUDPC) between treatments were analyzed using the Kruskal-Wallis rank sum test in the R environment [26]. The "DescTools" package [27] was used for Dunn's test computation as post hoc analysis ( $p<0.05$ significance level).

\section{Results and Discussion}

\subsection{Production of Deletion Mutants Lacking Fcrho1 Open Reading Frame}

To functionally characterize Fcrho1, deletion mutants were produced in two different $F$. circinatum strains, Fc072 and 011. In total, 8-10 transformants that exhibited mitotically stable resistance to hygromycin $\mathrm{B}$, indicating the correct genomic insertion of the $h y g R$ fragment, were identified for each fungal strain after transformation. Genomic DNA was extracted from 3 and 5 transformants obtained from the $\mathrm{F} 072$ and 011 strains, respectively. A PCR analysis using primers amplifying part of the Fcrho1 ORF (Table 1) revealed amplicons of the expected size (i.e., ectopic strains) in a single transformant of $\mathrm{Fc} 072$ while 3 transformants of 011 showed the amplicon corresponding to Fcrho1. Two independent Fcrho1 deletion mutants were, therefore, confirmed for each fungal strain. The DNA extractions and PCRs were repeated a second time to confirm the correct identification of Fcrho1 deletion mutant strains (i.e., the absence of Fcrho1 ORF and positive amplification of the hygR fragment; data not shown). These results represent, as far as we know, the first successful use of the OSCAR protocol to produce deletion mutants in F. circinatum. Use of this innovative protocol could be implemented for future gene characterization in PPC fungus as well as in other Fusarium spp.

\subsection{Phenotypic Characterization of Deletion Mutants}

To characterize the function of the previously in silico annotated gene Fcrho1 [3], we started by determining whether the vegetative growth of deletion mutants lacking Fcrho1 was affected. In F. graminearum, deletion of the Rho-type GTPase gene RHO1 was found to be lethal [12]. By contrast, in this study it was found that both $\Delta F c r h o 1 \mathrm{Fc} 072$ and $\Delta F c r h o 1011$ were able to grow (Figure 2) and also to sporulate (Table 2) in various culture media.

The in vitro assay showed that, although Fcrho1 is not an essential gene in F. circinatum, its absence greatly reduces the rate of mycelium growth $\left(X^{2}=24.43\right.$, d.f. $=5, p<0.01$; Figure 2$)$. More specifically, either $\Delta F c r h o 1 \mathrm{Fc} 072$ or $\Delta F c r h o 1011$ showed lower $\mathrm{G}$ than their corresponding wildtype and ectopic strains $(p<0.01$ in all cases). Mean growth rate varied neither among mutant strains $(p=0.74)$ nor in the rest of the pairwise comparisons ( $p>0.39$ in all cases) (Table 2). Otherwise, the colony size after a week of culturing $\left(A_{c}\right)$ varied among strains $\left(X^{2}=24.77\right.$, d.f. $\left.=5, p<0.01\right)$ being significantly smaller in both mutant strains ( $p \leq 0.01$ in all cases). No differences were found in $\mathrm{A}_{\mathrm{c}}$ among deletion mutants $(p=0.09)$ (Table 2). The range of growth rates and colony sizes reported here for wildtype and ectopic strains agreed with the expected pattern, i.e., similar growth rate as wildtype strains in the same nutritive medium (PDA) [28] and faster growth with respect to those cultured in Bavendamm medium, which simulates the chemical conditions of lignified tissues [24]. Hence the results reported here for ectopic strains confirmed that the OSCAR transformation procedure by itself caused no deleterious effect in F. circinatum. 
Reduced mycelial growth was not the only macroscopic change observed in F. circinatum upon deletion of Fcrho1. Colonies of the mutant strains also exhibited a more foamy appearance than their corresponding ectopic and wildtype strains (Figure 2). By contrast, the exploratory observations under a light microscope did not reveal noticeable changes in hyphal morphology (e.g., hyperbranching; Figure 3) as reported by Zhang et al. [12] in F. graminearum. A complex and variable role of GTPase proteins in the regulation of mycelial growth has been reported in fungal species. For example, similar to our results, F. oxysporum mutant strains lacking rho1 showed reduced growth on solid media [10]. Kwon et al. [29] studied the function of five members of the GTPase family in Aspergillus niger Tiegh. and found that each protein participates in fungal growth in a different manner. Accordingly, RhoA appears to regulate the formation of the germ tube while other GTPases such as RacA, RhoD and CftA contribute to hyphal tip elongation and mycelial growth. Zhang et al. [12] also reported changes in growth rate in the deletion mutants of four of the five Rho proteins evaluated. These authors also found the absence of aerial mycelium in rho4 mutants while deletion of rho2 resulted in slower growth and severe deformation of spores in minimal medium. Our results (i.e., unaltered hyphal architecture in parallel with evident changes in mycelium organization) suggest that the main function of Fchro1 should be the regulation of aerial mycelium formation as well as hyphal tip elongation.

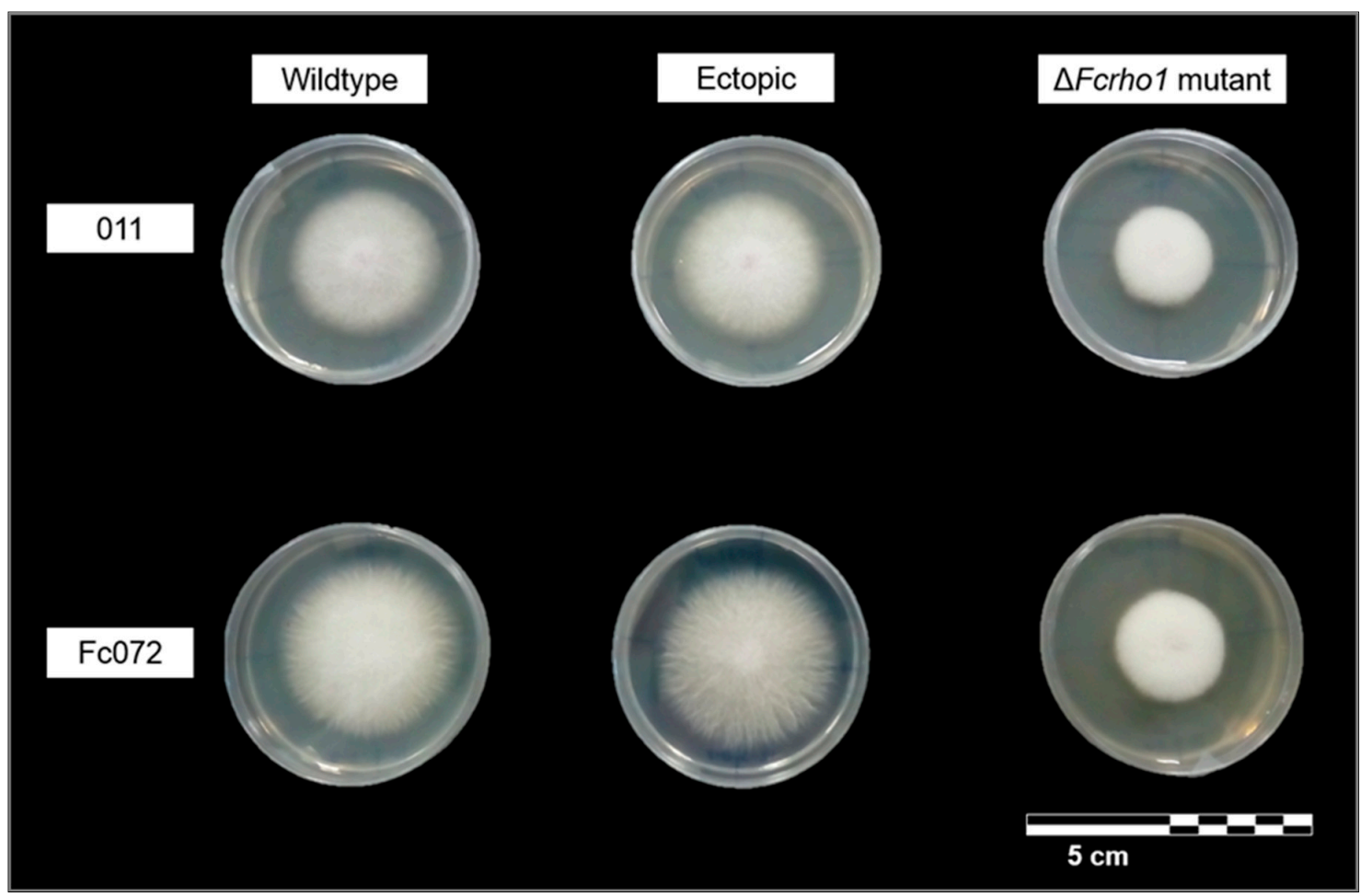

Figure 2. Colonies of F. circinatum growing in PDA (Appendix A) after one week of culturing. Wildtype (011 and Fc072) and ectopic strains (011ect5 and Fc072ect2) showed homogeneous growth and hairy appearance of colony. Mutant strains $(\Delta F c r h o 1011$ and $\Delta F c r h o 1 F c 072)$ showed lower growth rates and foamy macroscopic appearance.

The molecular mechanisms of virulence traits in PPC fungus are little understood yet. Genes whose deletion affects vegetative growth are often also involved in virulence as they regulate growth processes which are important for the colonization of the host. The functional characterization of candidate genes should, therefore, include in vivo assays that allow the identification of virulence factors. Bearing this in mind, in this work we performed an in vivo virulence assay to determine if the growth defects of our Fcrho1 deletion mutants resulted in a reduced ability to colonize the host. The severity of symptoms measured at $30 \mathrm{dpi}$ did not show significant variations among fungal strains (Figure 4) even though it was significantly lower in control seedlings $\left(X^{2}=35.57, p<0.01\right.$ in all cases), as expected. 
Table 2. In vitro characterization of F. circinatum strains. G: average daily growth rate during 7 days of culture; $\mathrm{A}_{\mathrm{c}}$ : area of fungal colony after culture for 7 days; $\mathrm{C}$ : spore density after $48 \mathrm{~h}$ of culture; $\mathrm{N}$ : germlings density after $48 \mathrm{~h}$ of culture. Small letters $(\mathrm{a}-\mathrm{b})$ denote significant differences according to Dunn's test $(p<0.05)$. Mean values and standard errors are shown.

\begin{tabular}{cccccc}
\hline Isolate & Strain & $\mathbf{G}\left(\mathbf{m m}^{\mathbf{2}} / \mathbf{d a y}\right)$ & $\mathbf{A c}\left(\mathbf{m m}^{\mathbf{2}}\right)$ & $\mathbf{C}\left(\right.$ Spores $\left./ \mathbf{m m}^{\mathbf{2}}\right)$ & $\mathbf{N}\left(\mathbf{G e r m l i n g s} / \mathbf{m m}^{\mathbf{2}}\right)$ \\
\hline \multirow{4}{*}{011} & wildtype & $764.55 \pm 76.04^{\mathrm{a}}$ & $4553.73 \pm 251.98^{\mathrm{a}}$ & $525.00 \pm 134.49^{\mathrm{a}}$ & $108.33 \pm 27.78^{\mathrm{a}}$ \\
& 011 ect5 & $744.38 \pm 41.38^{\mathrm{a}}$ & $4390.89 \pm 215.89^{\mathrm{a}}$ & $508.33 \pm 83.44^{\mathrm{a}}$ & $83.33 \pm 13.28^{\mathrm{a}}$ \\
& $\Delta$ Fcrho1011 & $331.89 \pm 30.72^{\mathrm{b}}$ & $1782.85 \pm 35.79^{\mathrm{b}}$ & $393.33 \pm 73.49^{\mathrm{a}}$ & $105.00 \pm 17.62^{\mathrm{a}}$ \\
\hline \multirow{2}{*}{ Fc072 } & wildtype & $793.53 \pm 91.55^{\mathrm{a}}$ & $4643.27 \pm 184.33^{\mathrm{a}}$ & $353.33 \pm 44.17^{\mathrm{a}}$ & $85.00 \pm 12.63^{\mathrm{a}}$ \\
& Fc072ect2 & $834.44 \pm 63.68^{\mathrm{a}}$ & $4791.97 \pm 234.82^{\mathrm{a}}$ & $370.00 \pm 61.63^{\mathrm{a}}$ & $71.66 \pm 15.01^{\mathrm{a}}$ \\
& $\Delta$ Fcrho1Fc072 & $302.85 \pm 50.27^{\mathrm{b}}$ & $1824.74 \pm 89.04^{\mathrm{b}}$ & $451.66 \pm 71.10^{\mathrm{a}}$ & $73.33 \pm 9.90^{\mathrm{a}}$ \\
\hline
\end{tabular}

Our results showed that Fcrho1 mutants were infective and ready to damage and even kill $P$. radiata seedlings (100\% re-isolation rate in each inoculation treatment). These findings show that Fcrho1 is not an essential regulator of pathogenicity in PPC fungus, although they do not rule out its plausible participation in the disease cycle. It should be noted that the studies performed so far have shown that some Rho proteins play crucial roles in virulence whereas others do not appear to be required for host colonization. For example, a comprehensive analysis of Rho proteins in F. graminearum determined that lack of FgCdc42 and FgRho4 activity strongly reduced in planta virulence. By contrast, mutant strains lacking the gene encoding FgRho3 maintained a capacity to damage flowering wheat heads to a similar degree as in the wildtype. A broader analysis of Rho GTPase family proteins in F. circinatum will be required to evaluate the function of this type of proteins in determination of vegetative growth and host colonization and whether the impact of particular genes has an overlapping effect. It should be also noted that the four additional genes annotated in silico by Muñoz-Adalia et al. [3] are also good candidates to investigate for their role in virulence in the PPC fungus.

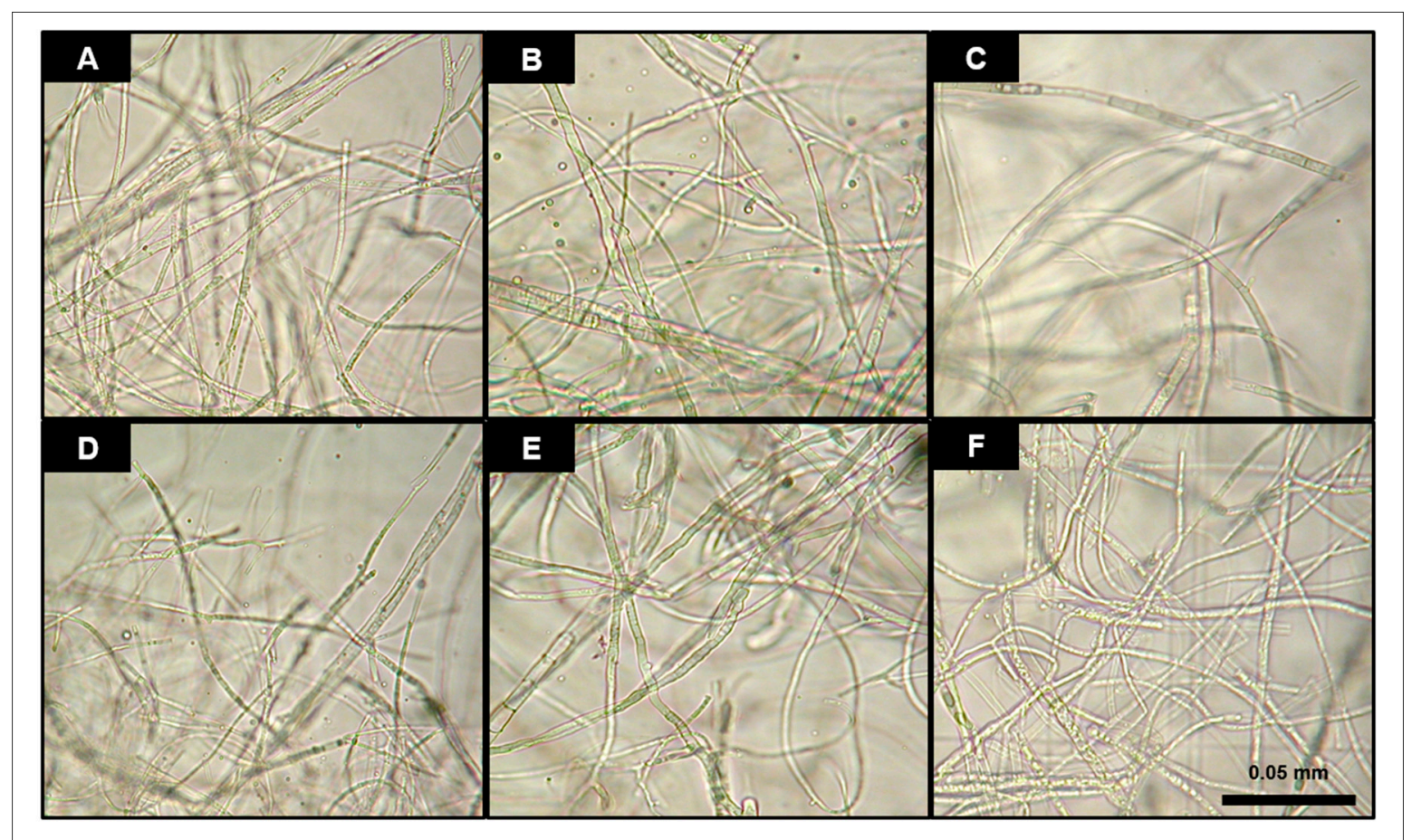

Figure 3. Microscopic morphology of hyphae in 40-days-old cultures. (A) 011 wildtype; (B) 011ect5; (C) $\Delta$ Fcrho1011; (D) Fc072 wildtype; (E) Fc072ect2; (F) $\Delta$ Fcrho1Fc072. Image processing: scaling to common size and $+20 \%$ brightness. 
Other developmental processes such as various aspects of asexual sporulation might play a role in the disease cycle of F. circinatum and were, therefore, analyzed in this study. Our results showed no significant effect of Fcrho1 deletion either on conidiation $\left(\mathrm{X}^{2}=2.86\right.$, d.f. $\left.=5, p=0.72\right)$ or spore germination $\left(\mathrm{X}^{2}=2.50\right.$, d.f. $=5, p=0.77$ ) (Table 2$)$. The role of Rho-family GTPases in spore production is variable among fungal species and in some cases contrasts sharply with our findings. For instance, in Magnaporthe grisea (T.T. Hebert) M.E. Barr deletion of the gene econding the Rho-family member Cdc42 strongly reduced conidiation and delayed spore germination [8]. In F. graminearum, on the other hand, deletion of different Rho protein genes caused dissimilar effects in spore production, an effect that also varied in different culture conditions [12]. Our in vitro results indicate that Fcrho1 does not regulate asexual reproduction. PPC fungus mutant strains lacking this gene were able to complete its asexual cycle and, therefore, to spread micro- and macroconidia through the plant tissues.

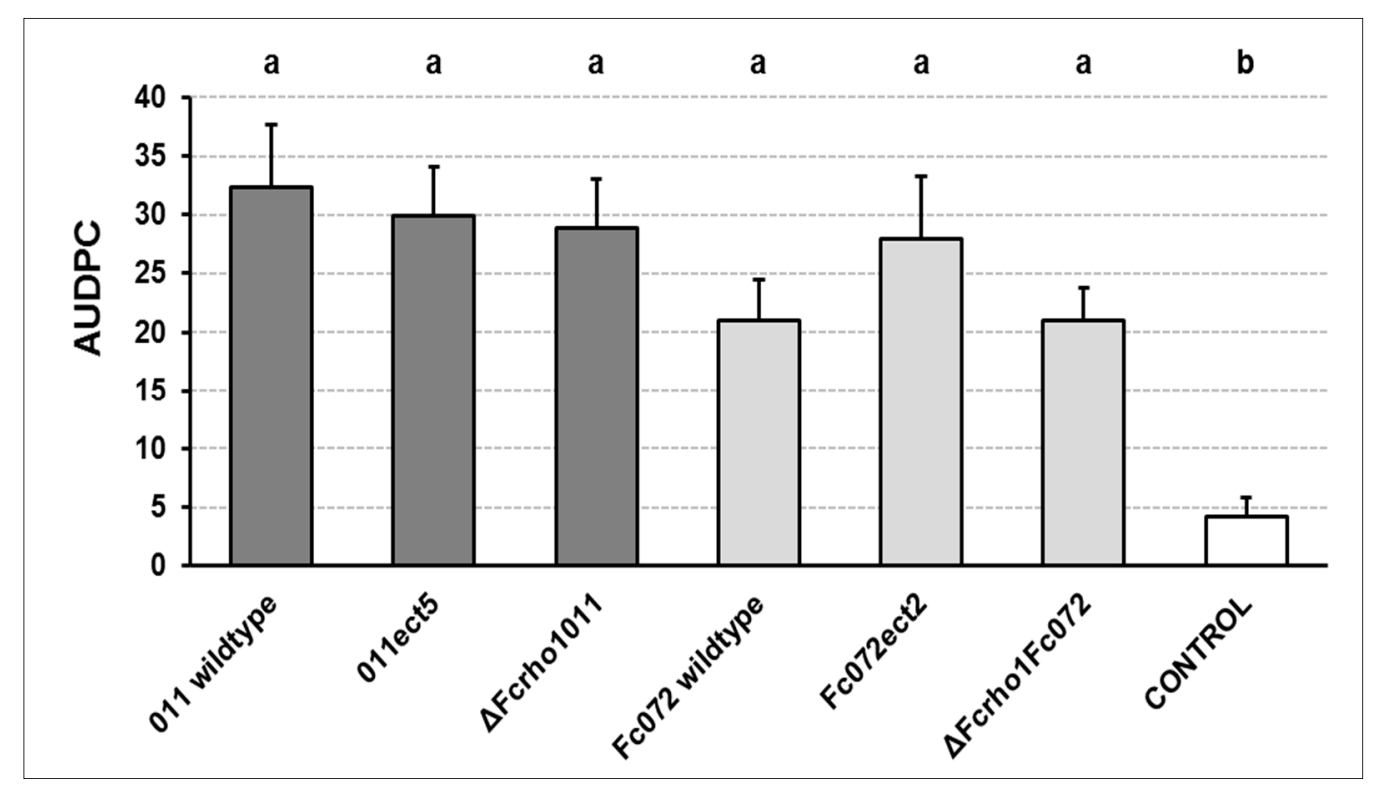

Figure 4. Area under the disease progress curve (AUDPC) of different fungal strains 30 days post inoculation (dpi). Lower-case letters $(a-b)$ indicate significant differences (Dunn's test, $p<0.05$ ). Comparisons between fungal strains are indicated by color of plot. Mean values and standard error are shown.

Mutants that show greatly reduced vegetative growth are frequently also affected in their ability to grow during pathogenic development, and thus in turn result in reduced virulence. Yet, we found that Fcrho1-lacking strains were as virulent as those having an intact copy of the gene (i.e., wildtype strains and ectopic transformants) (Figure 4). It should be noted that plant pathogenic fungi respond to multiple environmental signals, including those coming from the plant, and that the external signals regulating vegetative development and growth in the plant might differ considerably. A possible explanation of the results presented here is, therefore, that Fcrho1 could be involved only in the pathways that regulate hyphal elongation in response to environmental signals during vegetative growth. Hence, the mutants would respond normally to the signals regulating growth during the host-pathogen interaction, displaying normal growth in that condition. An alternative explanation could be found in the specific host used in our bioassay. Monterey pine is known as the most susceptible species to PPC [23] and the spatial-temporal analysis of infection provided by Martín-Rodrigues et al. [30] led to the opinion that the defense mechanisms of this pine are inefficient during trunk colonization by F. circinatum. Hence, it is possible that the severe damage observed in our virulence assay were due to the low resistance of $P$. radiata resulting in aggressive infection even for fungal strains with reduced growth rates. The use of an alternative host might clarify whether the observed pattern of pathogenicity is caused by the higher susceptibility of Monterey pine. In this 
sense, other pines such as stone pine (Pinus pinea L.) have shown a higher degree of resistance to the pathogen [31], becoming a complementary model for future inoculation trials.

In summary, in this study we successfully generated Fcrho1 deletion mutants of F. circinatum and used them to perform a preliminary characterization of this pathogenicity-related candidate gene in vitro and in vivo. Our results showed that Fcrho1 is not essential in host colonization, but its deletion has a great impact on vegetative growth rates in F. circinatum. By contrast, asexual reproduction was not affected upon gene deletion. Furthermore, mutant strains were able to effectively infect and cause damage to P. radiata seedlings. Additional studies will be required to fully establish the role of Fcrho1 and other Rho-family GTPases as virulence factors in the PPC fungus.

\section{Conclusions}

1. A modified version of the OSCAR protocol for generating a deletion construction in a single cloning step was successfully used in F. circinatum. This method, therefore, proved to be suitable for gene modifications in this phytopathogen. Furthermore, OSCAR was proved to be a useful methodology for the future functional characterization of pathogenicity-related genes in the PPC fungus.

2. The GTPase encoding gene Fcrho1 played an important role in regulating the vegetative growth of F. circinatum in a generalist solid medium. This gene seems to be involved in some aspects of vegetative growth such as hyphal tip elongation and aerial mycelium formation.

3. Fcrho1 is not essential for developing some functions in the lifecycle of F. circinatum, being deletion mutants able to grow, sporulate and colonize $P$. radiata seedlings. However, the high susceptibility of this pine species could also participate in the observed virulent development of mutant strains. In consequence, further research is required to clarify whether a lower growth rate in mutant strains could cause attenuated virulence in less susceptible hosts.

Author Contributions: E.J.M.-A., J.J.D., M.C.C., M.D.G.-P. and M.F. conceived and designed the experiments; M.C.C. and M.D.G.-P. supervised the molecular biology processes; J.J.D. and M.F. supervised both in vitro and in vivo assays; E.J.M.-A. and M.C.C. performed the laboratory analysis; E.J.M.-A. analyzed the data; E.J.M.-A. and M.D.G.-P. wrote the article; all authors reviewed the document.

Funding: This study was supported by two research projects: AGL2015-69370-R “Next Generation Sequencing (NGS) technologies for the study of Fusarium circinatum mycoviruses" (MINECO/FEDER, UE) and AGL2012-39912 "Biological control of Pine Pitch Canker disease by the use of Fusarium circinatum mycoviruses" (Ministerio de Economía y Competitividad). This article is based upon work from COST Action FP1406 PINESTRENGTH (Pine pitch canker-strategies for management of Gibberella circinata in greenhouses and forests), supported by COST (European Cooperation in Science and Technology). E. Jordán Muñoz-Adalia is a receipt of grants from the European Social Fund and from the Consejería de Educación de Castilla y León (JCyL) (ORDEN EDU /1083/2013). A scholarship granted by the University of Valladolid (Ayudas para estancias breves en el desarrollo de tesis doctorales convocatoria 2017; EB17) supported the mobility of E. Jordán Muñoz-Adalia. The work performed at the IHSM "La Mayora" was supported by research grant AGL2016-80048-R "The micovirus as tools for the biological control of Verticillium and Fusarium Wilts. Elucidating the mechanisms that regulate the virus-fungus-plant interaction" (Ministerio de Economía y Competitividad).

Acknowledgments: The authors thank J.M. Aragón (IHSM "La Mayora") as well as P. Martínez-Álvarez (Tragsatec) and J.C. Vinagrero (UVa) for their participation in laboratory tasks.

Conflicts of Interest: The authors declare no conflict of interest.

\section{Appendix A}

\section{Culture Media and Buffers Used in This Article}

- Induction medium: $1 \% v / v \mathrm{~K}$ buffer, $2 \% v / v \mathrm{M}-\mathrm{N}$ solution, $1 \% v / v \mathrm{CaCl}_{2}(1 \%$ w/v), $1 \% v / v$ $\mathrm{FeSO}_{4}(0.01 \% \mathrm{w} / \mathrm{v}), 0.5 \% \mathrm{v} / \mathrm{v}$ spore elements $\left(0.1 \% \mathrm{w} / v\right.$ of $\mathrm{ZnSO}_{4} \cdot 7 \mathrm{H}_{2} \mathrm{O}, \mathrm{H}_{3} \mathrm{BO}_{3}, \mathrm{CuSO}_{4} \cdot 5 \mathrm{H}_{2} \mathrm{O}$ and $\left.\mathrm{MnSO}_{4} \cdot 4 \mathrm{H}_{2} \mathrm{O}\right), 0.25 \% v / v \mathrm{NH}_{4} \mathrm{NO}_{3}(20 \%$ w/v), $1 \%$ v/v glycerol $(50 \% v / v), 4 \% v / v \operatorname{MES}(1 \mathrm{M})$ and $0.5 \% w / v$ glucose $(2 \mathrm{M})$. Adjust the medium at $\mathrm{pH}=6$. 
- LB: $10 \% w / v$ triptone, $5 \% w / v$ yeast extract and $10 \% w / v \mathrm{NaCl}(99 \% w / v)$.

- Minimum medium: $0.1 \% v / v \mathrm{~K}$ buffer $\left(20 \% w / v \mathrm{~K}_{2} \mathrm{HPO}_{4}\right.$ and $\left.14.5 \% w / v \mathrm{KH}_{2} \mathrm{PO}_{4} ; \mathrm{pH}=7\right)$, $2 \% \mathrm{M}-\mathrm{N}$ solution $\left(3 \% w / v \mathrm{MgSO}_{4} \cdot 7 \mathrm{H}_{2} \mathrm{O}\right.$ and $\left.1.5 \% w / v \mathrm{NaCl}\right), 0.01 \% v / v \mathrm{CaCl}_{2}(10 \% w / v), 1 \% v / v$ $\mathrm{FeSO}_{4}(0.01 \% w / v), 0.5 \% v / v$ spore elements, $2.5 \% v / v \mathrm{NH}_{4} \mathrm{NO}_{3}(20 \% w / v), 0.1 \% w / v$ glucose (2 M).

- PDA: $3.9 \% w / v$ potato dextrose agar.

- PDB: $2.8 \% w / v$ potato dextrose broth.

- Selection medium: $3.9 \% w / v$ potato dextrose agar, $0.05 \% v / v$ hygromycin $B, 0.2 \% v / v$ cefotaxim, $0.1 \% v / v$ moxalactum and $0.06 \% w / v$ streptomycin.

- TENS: $1 \% v / v \mathrm{NaOH}(10 \mathrm{~N}), 5 \% v / v$ SDS $(10 \% v / v), 1 \%$ Tris base $(1 \mathrm{M} ; \mathrm{pH}=8)$ and $0.25 \% v / v$ EDTA $(0.5 \mathrm{M} ; \mathrm{pH}=8)$.

- YEPS: $1 \% w / v$ yeast extract, $2 \% w / v$ bacto-peptone and $2 \% w / v$ sucrose.

\section{References}

1. Wingfield, M.J.; Hammerbacher, A.; Ganley, R.J.; Steenkamp, E.T.; Gordon, T.R.; Wingfield, B.D.; Coutinho, T.A. Pitch canker caused by Fusarium circinatum-A growing threat to pine plantations and forests worldwide. Australas. Plant Pathol. 2008, 37, 319-334. [CrossRef]

2. Bezos, D.; Martínez-Álvarez, P.; Fernández, M.; Diez, J.J. Epidemiology and management of Pine Pitch Canker Disease in Europe-A review. Balt. For. 2017, 23, 279-293.

3. Muñoz-Adalia, E.J.; Fernández, M.; Wingfield, B.D.; Diez, J.J. In silico annotation of five candidate genes associated with pathogenicity in Fusarium circinatum. For. Pathol. 2018, 48. [CrossRef]

4. Wingfield, B.D.; Steenkamp, E.T.; Santana, Q.C.; Coetzee, M.P.A.; Bam, S.; Barnes, I.; Beukes, C.W.; Chan, W.Y.; de Vos, L.; Fourie, G.; et al. First fungal genome sequence from Africa: A preliminary analysis. S. Afr. J. Sci. 2012, 108, 1-9. [CrossRef]

5. Araujo-Palomares, C.L.; Richthammer, C.; Seiler, S.; Castro-Longoria, E. Functional characterization and cellular dynamics of the CDC-42-RAC-CDC-24 module in Neurospora crassa. PLoS ONE 2011, 6. [CrossRef] [PubMed]

6. Iden, S.; Collard, J.G. Crosstalk between small GTPases and polarity proteins in cell polarization. Nat. Rev. Mol. Cell Biol. 2008, 9, 846-859. [CrossRef] [PubMed]

7. Chen, J.; Zheng, W.; Zheng, S.; Zhang, D.; Sang, W.; Chen, X.; Li, G.; Lu, G.; Wang, Z. Rac1 is required for pathogenicity and Chm1-dependent conidiogenesis in rice fungal pathogen Magnaporthe grisea. PLoS Pathog. 2008, 4. [CrossRef] [PubMed]

8. Zheng, W.; Zhao, Z.; Chen, J.; Liu, W.; Ke, H.; Zhou, J.; Lu, G.; Darvill, A.G.; Albersheim, P.; Wu, S.; et al. A Cdc42 ortholog is required for penetration and virulence of Magnaporthe grisea. Fungal Genet. Biol. 2009, 46, 450-460. [CrossRef] [PubMed]

9. Rolke, Y.; Tudzynski, P. The small GTPase Rac and the p21-activated kinase Cla4 in Claviceps purpurea: Interaction and impact on polarity, development and pathogenicity. Mol. Microbiol. 2008, 68, 405-423. [CrossRef] [PubMed]

10. Martínez-Rocha, A.L.; Roncero, M.I.G.; López-Ramirez, A.; Mariné, M.; Guarro, J.; Martínez-Cadena, G.; Di Pietro, A. Rho1 has distinct functions in morphogenesis, cell wall biosynthesis and virulence of Fusarium oxysporum. Cell. Microbiol. 2008, 10, 1339-1351. [CrossRef] [PubMed]

11. Bluhm, B.H.; Zhao, X.; Flaherty, J.E.; Xu, J.-R.; Dunkle, L.D. RAS2 Regulates Growth and Pathogenesis in Fusarium graminearum. Mol. Plant-Microbe Interact. 2007, 20, 627-636. [CrossRef] [PubMed]

12. Zhang, C.; Wang, Y.; Wang, J.; Zhai, Z.; Zhang, L.; Zheng, W.; Zheng, W.; Yu, W.; Zhou, J.; Lu, G.; et al. Functional characterization of Rho family small GTPases in Fusarium graminearum. Fungal Genet. Biol. 2013, 61, 90-99. [CrossRef] [PubMed]

13. Vainio, E.J.; Martínez-Álvarez, P.; Bezos, D.; Hantula, J.; Diez, J.J. Fusarium circinatum isolates from northern Spain are commonly infected by three distinct mitoviruses. Arch. Virol. 2015, 160, 2093-2098. [CrossRef] [PubMed] 
14. Paz, Z.; García-Pedrajas, M.D.; Andrews, D.L.; Klosterman, S.J.; Baeza-Montañez, L.; Gold, S.E. One Step Construction of Agrobacterium-Recombination-ready-plasmids (OSCAR), an efficient and robust tool for ATMT based gene deletion construction in fungi. Fungal Genet. Biol. 2011, 48, 677-684. [CrossRef] [PubMed]

15. Gold, S.E.; Paz, Z.; García-Pedrajas, M.D.; Glenn, A. Rapid Deletion Production in Fungi via Agrobacterium Mediated Transformation of OSCAR Deletion Constructs. J. Vis. Exp. 2017, 12. [CrossRef] [PubMed]

16. Untergasser, A.; Cutcutache, I.; Koressaar, T.; Ye, J.; Faircloth, B.C.; Remm, M.; Rozen, S.G. Primer3-New capabilities and interfaces. Nucleic Acids Res. 2012, 40, e115. [CrossRef] [PubMed]

17. García-Pedrajas, M.D.; Paz, Z.; Andrews, D.L.; Baeza-Montañez, L.; Gold, S.E. Rapid Deletion Plasmid Construction Methods for Protoplast and Agrobacterium-based Fungal Transformation Systems. In Laboratory Protocols in Fungal Biology: Current Methods in Fungal Biology; Gupta, V.K., Tuohy, M.G., Eds.; Springer: Berlin, Germany, 2013; pp. 375-394.

18. Khang, C.H.; Park, S.Y.; Lee, Y.H.; Kang, S. A dual selection based, targeted gene replacement tool for Magnaporthe grisea and Fusarium oxysporum. Fungal Genet. Biol. 2005, 42, 483-492. [CrossRef] [PubMed]

19. Sarmiento-Villamil, J.L.; Prieto, P.; Klosterman, S.J.; García-Pedrajas, M.D. Characterization of two homeodomain transcription factors with critical but distinct roles in virulence in the vascular pathogen Verticillium dahliae. Mol. Plant Pathol. 2018, 19, 986-1004. [CrossRef] [PubMed]

20. Hellens, R.; Mullineaux, P.; Klee, H. A guide to Agrobacterium binary Ti vectors. Trends Plant Sci. 2000, 5, 446-451. [CrossRef]

21. Vainio, E.J.; Korhonen, K.; Hantula, J. Genetic variation in Phlebiopsis gigantea as detected with random amplified microsatellite (RAMS) markers. Mycol. Res. 1998, 102, 187-192. [CrossRef]

22. Correll, J.C.; Gordon, T.R.; McCain, A.H.; Fox, J.W.; Koehler, C.S.; Wood, D.L.; Schultz, M.E. Pitch Canker Disease in California-Pathogenicity, Distribution, and Canker Development on Monterey Pine (Pinus radiata). Plant Dis. 1991, 75, 676-682. [CrossRef]

23. Martínez-Álvarez, P.; Pando, V.; Diez, J.J. Alternative species to replace Monterey pine plantations affected by pitch canker caused by Fusarium circinatum in northern Spain. Plant Pathol. 2014, 63, 1086-1094. [CrossRef]

24. Muñoz-Adalia, E.J.; Flores-Pacheco, J.A.; Martínez-Álvarez, P.; Martín-García, J.; Fernández, M.; Diez, J.J. Effect of mycoviruses on the virulence of Fusarium circinatum and laccase activity. Physiol. Mol. Plant Pathol. 2016, 94, 8-15. [CrossRef]

25. Leslie, J.F.; Summerell, B.A. The Fusarium Laboratory Manual; Blackwell Publishing Professional: Ames, IA, USA, 2006; p. 388.

26. R Development Core Team. R: A Language and Environment for Statistical Computing; R Development Core Team: Vienna, Austria, 2015; Volume 55, pp. 275-286.

27. Signorell, A.; Aho, K.; Anderegg, N.; Aragon, T.; Arppe, A.; Baddeley, A.; Bolker, B.; Caeiro, F.; Champely, S.; Chessel, D.; et al. DescTools: Tools for Descriptive Statistics. 2015. Available online: https:/ / cran.r-project. org/web/packages/DescTools/index.html (accessed on 20 April 2018).

28. Flores-Pacheco, J.A.; Muñoz-Adalia, E.J.; Martínez-Álvarez, P.; Pando, V.; Diez, J.J.; Martín-García, J. Effect of mycoviruses on growth, spore germination and pathogenicity of the fungus Fusarium circinatum. For. Syst. 2017, 26. [CrossRef]

29. Kwon, M.J.; Arentshorst, M.; Roos, E.D.; Van Den Hondel, C.A.M.J.J.; Meyer, V.; Ram, A.F.J. Functional characterization of Rho GTPases in Aspergillus niger uncovers conserved and diverged roles of Rho proteins within filamentous fungi. Mol. Microbiol. 2011, 79, 1151-1167. [CrossRef] [PubMed]

30. Martín-Rodrigues, N.; Espinel, S.; Sanchez-Zabala, J.; Ortíz, A.; González-Murua, C.; Duñabeitia, M.K. Spatial and temporal dynamics of the colonization of Pinus radiata by Fusarium circinatum, of conidiophora development in the pith and of traumatic resin duct formation. New Phytol. 2013, 198, 1215-1227. [CrossRef] [PubMed]

31. Iturritxa, E.; Ganley, R.J.; Raposo, R.; García-Serna, I.; Mesanza, N.; Kirkpatrick, S.C.; Gordon, T.R. Resistance levels of Spanish conifers against Fusarium circinatum and Diplodia pinea. For. Pathol. 2013, 43, 488-495. [CrossRef]

(C) 2018 by the authors. Licensee MDPI, Basel, Switzerland. This article is an open access article distributed under the terms and conditions of the Creative Commons Attribution (CC BY) license (http:/ / creativecommons.org/licenses/by/4.0/). 